\title{
A arte nacional em Painel (1950): entre o presente e 0 passado
} The national art in Painel (1950): between the present and the past

Igor David dos Santos ${ }^{1}$ 
Resumo: este artigo analisa o curta-metragem Painel (1950), dirigido por Lima Barreto, baseado no painel Tiradentes, pintado por Cândido Portinari. Esmiuçando elementos narrativos, visuais e sonoros, nosso objetivo é analisar a maneira com que o filme cria uma visualidade de seu tempo ligada à modernidade - por meio da arte moderna, arquitetura, design, música -, ao mesmo tempo em que trata de um evento do passado, a Inconfidência Mineira.

Palavras-chave: Painel; Lima Barreto; documentário.

Abstract: This article analyzes the short film Painel (1950, directed by Lima Barreto), which is based on the Tiradentes panel painted by Candido Portinari. Examining narrative, visual, and sonorous elements, this article aims to analyze how the movie creates a visuality of its time linked to the modernity - through the modern art, architecture, design, music -, and at the same time discusses a past event, the Inconfidência Mineira.

Keywords: Painel; Lima Barreto; documentary. 


\section{Introdução}

Com este artigo pretendemos analisar historicamente a obra fílmica Painel (1950), de Lima Barreto - primeiro curta-metragem lançado pela Companhia Cinematográfica Vera Cruz - visando compreender de que modo a película trata de temas referentes ao passado nacional, ao mesmo tempo que procura construir a visualidade de um presente que se propunha moderno.

Destacamos que, durante a década de 1940, a capital paulista passou por um intenso crescimento industrial e urbano. O desenvolvimento econômico gestou uma série de investimentos - por parte da burguesia industrial, recém-formada no campo artístico. Entre os empreendimentos voltados à arte e financiados pela iniciativa privada, podemos citar: a fundação do Museu de Arte de São Paulo (Masp) em 1947; a fundação da Escola de Arte Dramática (EAD) e do Teatro Brasileiro de Comédia (TBC) em 1948; e a criação do Museu de Arte Moderna (MAM) em 1949.

É nesse panorama que situa-se a criação da Vera Cruz, em 1949, assim como o desenvolvimento de um campo cinematográfico que se contrapunha às décadas de 1930 e 1940, quando o cinema praticamente inexistia na cidade de São Paulo. Entre os anos de 1949 e 1950, foram criadas cinco produtoras, entre elas: a Maristela, a Multifilmes e a Vera Cruz.

A proposta da Vera Cruz visava à criação de um cinema diferente daquele que existia no Brasil naquela época, inspirando-se em modelos industriais de produção. A Companhia almejava não só a distribuição em mercado nacional, mas atingir os padrões de exportação através do alto capital investido em equipamentos e pessoal técnico.

No que se refere ao nosso recorte que busca os elementos utilizados pelo filme para edificar o presente ao tematizar o passado, além da obra de Maria Rita Galvão (1981), destacamos as obras de Ismail Xavier (2007) e Célia Tolentino (2001), que analisam a película O cangaceiro (1953), de Lima Barreto, na qual encontramos questões correlatas. Ismail Xavier (2007) em sua obra Sertão Mar: Glauber Rocha e a estética da fome dedica extensa análise ao filme $O$ cangaceiro. O autor aponta que foi necessária uma transformação social, assim como a industrialização do cinema, para que se pudesse tratar do cangaço, a exemplo do que ocorrera no cinema norte-americano com os filmes de western. Foi possível, assim, tratá-lo enquanto um passado "bárbaro" superado pela civilizada coetaneidade. O estudo de Célia Tolentino a respeito das mudanças nas representações do rural no cinema brasileiro durante os anos 1950-1960 demonstra que o cinema industrial em 1950 trata do rural como elemento representativo do nacional, mas a partir de um "narrador urbano 
e burguês que fala do outro e não de si” (TOLENTINO, 2001, p. 23). A autora demonstra que essa postura, ao se afirmar diante do "outro" ressaltando sua postura cosmopolita, revela o quanto "o peso da 'civilização do café' pairava ainda no ar, seguindo os burgueses da década de 1950, como uma tradição não superada de todo pelo industrialismo" (TOLENTINO, 2001, p. 64). Tais eixos já foram seguidos em nossa dissertação de mestrado (SANTOS, 2015).

Como veremos, Painel (1950) trata de um tema referente ao passado nacional, mas não sem antes afirmar que o narrador se estabelece em um presente moderno. Para fins de argumentação, seguiremos o seguinte roteiro: traçar um breve contexto do local onde o filme foi rodado e do painel Tiradentes; distinguir como o espaço cênico contribui para gerar na película a impressão de modernidade e sugerindo a ideia de bom gosto ao espectador; analisar o papel da trilha musical; interpretar como o tema da Inconfidência Mineira é utilizado em Painel.

Dessa maneira, objetivamos desenvolver a análise de como as artes, aliadas à figura de Tiradentes e da Inconfidência Mineira como elementos representativos do passado nacional, foram situados por aquele presente que ansiava por modernidade.

\section{Painel}

O filme Painel (1950), de Lima Barreto, foi rodado na cidade de Cataguases, situada na Zona da Mata Mineira. Essa cidade pôde adquirir ares de modernidade ainda no início do século XX, com a criação de indústrias têxteis na região e que se intensificou até meados do século, apesar de ter se mantido relativamente pequena, mesmo considerando os padrões urbanos da época. Assim, ainda na década de 1920, a cidade pôde entrar em diálogo com o Movimento Modernista de 1922 por meio da criação da Revista Verde, que circulou entre 1927 e 1929. Nesse mesmo período ocorreram as primeiras produções do cineasta Humberto Mauro em Cataguases, só possível por meio do investimento inicial concedido por comerciantes locais. Em 1927 foi filmada a premiada produção Thesouro perdido (1927), que aproveitou cenários e atores locais.

Um novo ímpeto de modernidade se deu na cidade no decorrer dos anos 1940, agora pelo literato Francisco Inácio Peixoto, pertencente à família enriquecida com a indústria têxtil e ex-integrante do grupo surgido em torno da Revista Verde. Essa nova fase buscou importar artistas, arquitetos e paisagistas para construírem projetos de vanguarda que pudessem modificar a paisagem urbana da cidade. Conforme Santos e Lage (2005), além de Oscar Niemeyer, que fora convidado por Peixoto para projetar sua residência em 1943, 
arquitetos como Carlos Leão, Francisco Bolonha, Aldary Toledo, os irmãos Roberto, Gilberto Lemos, Luzimar Cerqueira de Goes Telles, Flávio Almada; paisagistas como Burle Marx, Carlos Percy e o próprio Bolonha; o designer de móveis Joaquim Tenreiro; artistas como Anisio Medeiros, Portinari, Di Cavalcanti, Djanira, Iberê Camargo, Vicente do Rego Monteiro, Cícero Dias, Emeric Marcier, Jan Zach, Bruno Giorgi, irão povoar a cidade com suas obras. (SANTOS; LAGE, 2005, s.p.)

Por sua vez, o Colégio de Cataguases foi encomendado por Francisco Inácio Peixoto para que Niemeyer o projetasse, tendo concluído o desenho do projeto em 1944. Conforme Silva (2005, p. 42-49)², o desenho proposto pelo arquiteto primava pela funcionalidade, assim como se mostrou inovador diante dos prédios escolares existentes no Brasil até então, esses que seguiam o modelo panóptico, no qual a arquitetura corrobora para o exercício da vigilância e do controle disciplinar. Aqui a solução funcional se dá pelo desenho que aproveita a mobilidade do espaço.

Em seguida, Niemeyer pede a Peixoto para que convidasse Cândido Portinari para pintar o painel que se situaria no saguão do Colégio. Portinari já havia se firmado enquanto pintor na década de 1930, sendo inclusive premiado nos Estados Unidos, e no final da mesma década ocorreu a exposição de sua obra no Museu de Arte Moderna de Nova York. Tal convite havia se dado nos anos de crise provocados pela Segunda Guerra e na chamada Política da Boa Vizinhança ${ }^{3}$ implantada pelo governo ianque, procurando aproximar-se da América Latina principalmente através de intercâmbios culturais (AMARAL, 2003).

No contexto da Política da Boa Vizinhança, Portinari é convidado, juntamente com uma série de artistas brasileiros - entre eles os músicos Camargo Guarnieri e Francisco Mignone ${ }^{4}$, que posteriormente comporiam para filmes da Vera Cruz -, para expor na Feira de Nova York, realizada no MoMA, em 1939. A partir daí, no decorrer dos anos 1940 até 1947, são exibidas cerca de dezoito exposições individuais de Portinari em diversas cidades norte-americanas 5 .

A situação se modifica em 1947, quando Portinari concorre ao cargo de senador pelo Partido Comunista Brasileiro. No entanto, com o acirramento da

\footnotetext{
${ }^{2} \mathrm{~A}$ autora realizou um estudo sobre as memórias de ex-alunos do Colégio Cataguases buscando compreender como se davam as relações pedagógicas, assim como a interação dos alunos com e a partir do espaço. Conforme a autora, o painel de Tiradentes ficou no Colégio até o ano de 1977, quando foi transferido para São Paulo e hoje se encontra no Memorial da América Latina (Cf. SILVA, 2005).

${ }^{3}$ Cf. Tota (2000).

${ }^{4}$ Sobre a relação estabelecida entre os músicos modernistas brasileiros e a Política da Boa Vizinhança e os EUA nos anos 1930-1940, conferir Egg (2013).

5Listagem disponível em: <https://goo.gl/3sJ3S2>. Acesso em: 26 mar. 2018.
} 
Guerra Fria e com o alinhamento do Governo Dutra aos Estados Unidos, o partido entra na ilegalidade, e Portinari passa oito meses refugiado no Uruguai, quando volta ao Brasil a convite de Inácio Peixoto para pintar o painel de Tiradentes (Figura 1), o qual é o foco do documentário em questão.

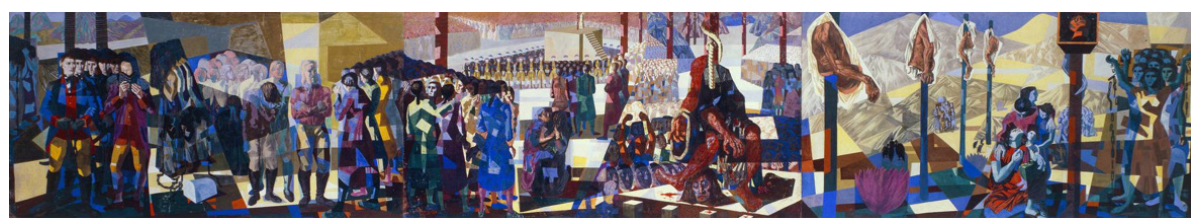

Figura 1: Painel Tiradentes.

Fonte: Portinari (1948)

O painel (Figura 1) de grandes dimensões, com cerca de três metros de altura por dezessete de largura, ocupava uma parede no saguão nobre do Colégio de Cataguases. Conforme a análise desenvolvida por Maria Milliet (1998, p. 223-256), há uma série de elementos que remetem a obra a uma tradição clássica na pintura, tais como: profundidade, perspectiva, inserção de elementos simbólicos e construção de uma narrativa contínua, na qual se apresentam ações que se deram em tempos e espaços distintos.

No painel, a ênfase não recai no herói individual, mas nos grandes grupos corais que participam direta ou indiretamente dos acontecimentos. Ainda nesse sentido, a obra evita a mitificação da forca, tão recorrente na iconografia que a antecede (MILLIET, 1998, p. 252) com o intuito de heroicizar Tiradentes, mas coloca em primeiro plano o corpo esquartejado, o que gerou críticas na época.

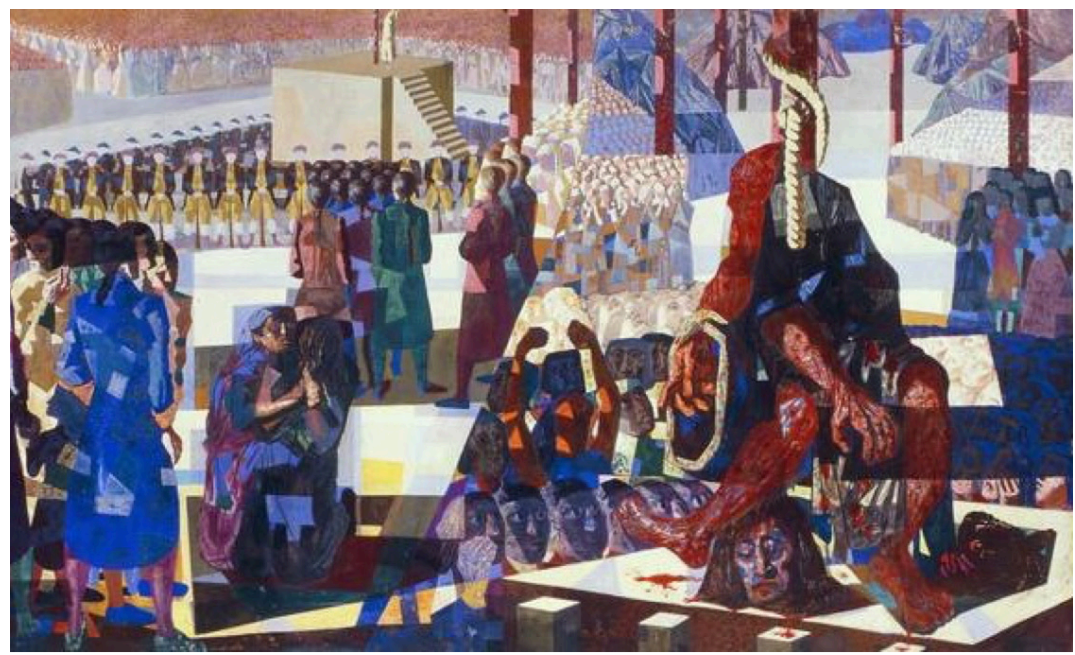

Figura 2: Painel Tiradentes, detalhe: o enforcamento e o corpo esquartejado de Tiradentes. Fonte: Portinari (1948) 
A disposição dos elementos no conjunto da sequência narrativa confere ao espectador uma posição participativa, conforme disserta Milliet, na qual:

Às cenas agrega-se ou contrapõe-se o grupo ou mesmo a massa popular e quem olha a obra participa da mesma condição de espectador. Tudo funciona como passos de uma paixão não religiosa, mas social. A história assim presenciada deixa de ser passado, atualiza-se. (MILLIET, 1998, p. 228)

Conforme esclarece Milliet, devemos considerar as condições de exposição da obra, uma vez que os murais de Portinari partiam de adequações específicas para determinados temas e locais onde suas obras seriam instaladas. Dessa forma, suas amplas dimensões e sua disposição em um saguão escolar visavam trazer o tema ao presente do espectador através da educação pela imagem.

Assim, atentos à convergência existente nesse cenário entre artistas e obras representativas da modernidade, é que procuraremos traçar nossa análise que se desenvolverá nas linhas a seguir, procurando identificar o modo com que tais elementos foram aproveitados pelo filme.

\section{A arquitetura moderna e o espaço cênico como personagens}

Em Painel, os letreiros iniciais informam ao espectador que a película é baseada “no 'Tiradentes' de Cândido Portinari”. Dedicam agradecimentos ao "Colégio de Cataguases", onde a obra foi rodada, assim como inserem uma epígrafe de Álvares de Azevedo que informa: "Era o filho do povo! O sangue ardente às faces lhe assomava, incandescente, quando cismava do Brasil na sina...” (1999, p. 397)6. Dessa forma, já se explicita o tema, assim como a epígrafe inserida reforça tanto a relevância em abordá-lo quanto o posicionamento assumido.

Em seguida, há uma aproximação gradual que pretende apresentar o locus no qual ocorre a ação. Essa se dá através de três planos (Figura 3). Assim, é possível pensarmos a própria construção do Colégio como uma personagem que se apresenta nesse primeiro momento. Primeiramente surgem várias folhas que vão sendo removidas da frente da objetiva, revelando um plano aberto. O segundo plano traz um enquadramento mais próximo do Colégio, enquanto o terceiro mostra em detalhe parte de sua arquitetura. Os três planos são acompanhados por efeitos sonoros que compõem a paisagem, através de pássaros e do cacarejar de um galo.

${ }^{6}$ Trata-se do poema "Pedro Ivo", dedicado a Pedro Ivo Veloso da Silveira, revolucionário pernambucano que participou da Revolução Praieira de Pernambuco. 

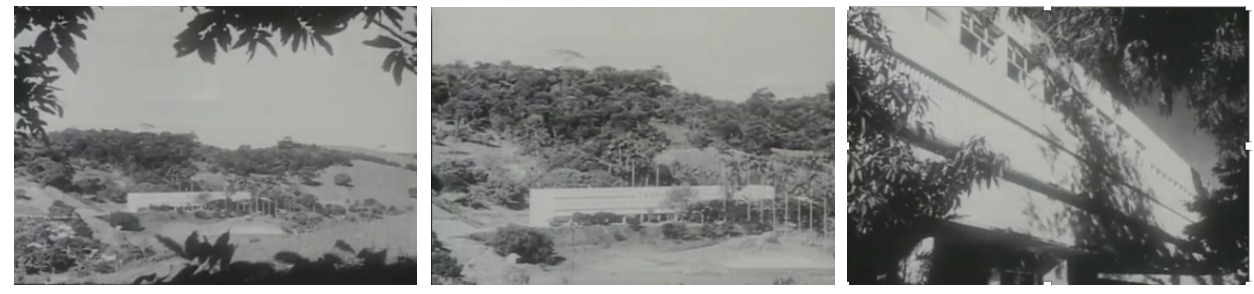

Figura 3: Painel (1950) - o Colégio de Cataguases.

Após a apresentação externa, a câmera nos leva a conhecer o interior das dependências, continuando com sua construção espacial que visa expor a arquitetura da construção (Figura 4). Nesse ponto o som ambiente cessa conforme as portas de entrada vão se abrindo. Até então os planos eram fixos, mas, com o intuito de destacar a rampa de acesso ao piso superior, a câmera faz um movimento vertical, de baixo para cima, em seu próprio eixo. Em seguida detalha um corrimão e no próximo plano enquadra nova rampa com uma porta ao fundo. As rampas mereciam um destaque especial até mesmo pelo seu ineditismo, conforme salientado por Silva (2005), e por se relacionarem ao moderno. Dessa forma, somos conduzidos através do olhar da câmera a um passeio em seu interior e logo chegamos à porta de entrada de uma sala de aula, onde se dá o mote da narrativa.
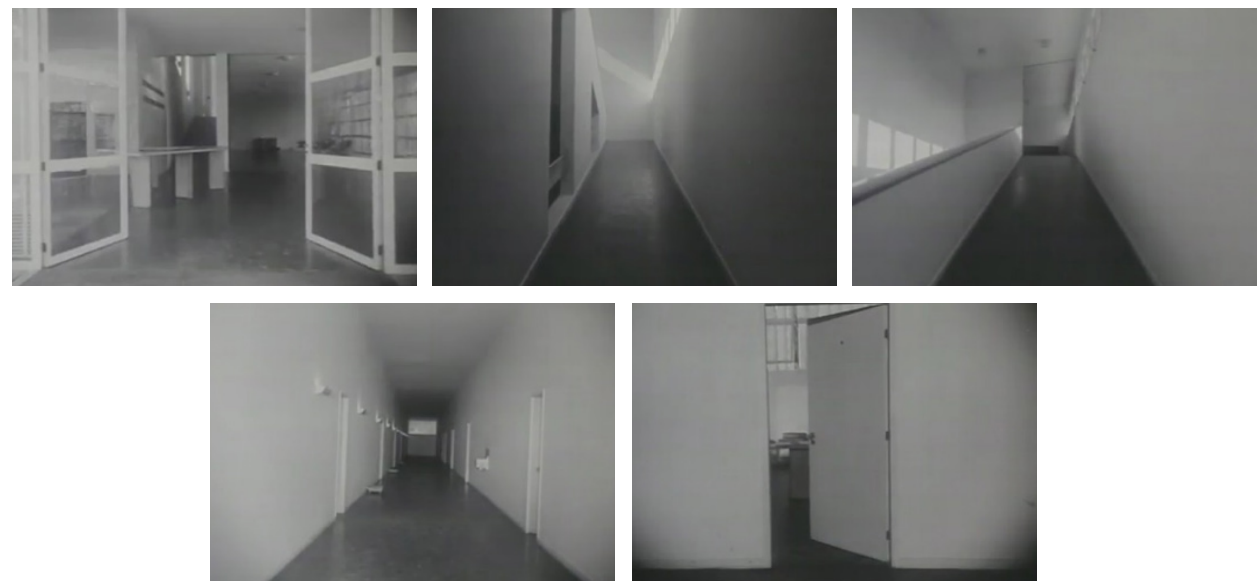

Figura 4: Painel (1950) - rampas e corredores do interior do Colégio.

O desenvolvimento da arquitetura moderna no Brasil se iniciou no final da década de 1920, quando, em 1929, ocorre a passagem de Le Corbusier pelo Brasil e a nomeação de Lúcio Costa para a direção da Escola de Belas Artes. A princípio, este arquiteto traça uma reformulação no currículo que até então era voltado ao período 
neocolonial brasileiro, inserindo na pauta os principais difusores da arquitetura moderna do século XX que, além de Le Corbusier, eram Gropius e Mies van der Rohe (FICHER; ACAYABA, 1982, p. 9-25).

Com a exceção de Le Corbusier, tais arquitetos eram ligados à escola alemã conhecida como Bauhaus, que agregou artistas de diversos campos entre 1919 e 1933. O grupo da Bauhaus se desenvolve como uma resposta imediata ao pós-guerra, no qual a Alemanha saiu derrotada. A tônica dos artistas, sobretudo no que diz respeito à arquitetura, se deu em torno das noções de "racionalidade" e "funcionalismo":

Viver civilizadamente significa viver racionalmente, colocando e resolvendo cada questão em termos dialéticos. A racionalidade deve enquadrar as grandes e pequenas ações da vida: racionais devem ser a cidade em que se vive, a casa em que se mora, a mobília e os utensílios que se empregam, a roupa que se veste. (ARGAN, 2010, p. 270)

Portanto, para além da construção arquitetônica em si, o movimento pensava em todo o contexto no qual ela se inseria, tanto no plano urbanístico quanto no interior das dependências. A cidade era entendida como um organismo produtivo e que deveria ser racionalmente otimizada, com vistas à ampliação de seu rendimento através de um melhor planejamento de mobilidade e funcionalidade do espaço ${ }^{7}$.

Conforme Ficher e Acayaba (1982, p. 10), no decorrer da década de 1930:

a expressão Arquitetura Racionalista veio a ter entre os arquitetos brasileiros um significado bastante flexível: seria, de forma sucinta, a arquitetura preconizada por Gropius, Mies Van der Rohe, Le Corbusier e Oud, [...] os arquitetos brasileiros, nesta primeira etapa, davam preferências às formas geométricas claramente definidas, à separação entre estrutura e vedação, permitindo maior liberdade no agenciamento interno dos edifícios, ao uso sistemático de pilotis, aos panos de vidros contínuos, ao invés das janelas tradicionais, e a integração da arquitetura com o entorno pelo paisagismo e com as outras artes plásticas pelo emprego de murais, painéis de azulejo decorado e escultura em substituição à decoração aplicada.

Ora, grande parte de tal enumeração está presente no Colégio de Cataguases, onde se acrescentam o paisagismo de Burle Marx e o mobiliário projetado por Joaquim Tenreiro, conforme veremos em seguida. Acrescenta-se que Niemeyer já vinha desenvolvendo trabalhos ao lado dos pioneiros da arquitetura moderna brasileira desde meados dos anos 1930 e que no início dos anos 1940 desenvolveu projetos

${ }^{7}$ Sobre o funcionalismo na arquitetura e no urbanismo na primeira metade do século XX, conferir Argan (2010, p. 263-300). 
governamentais para a cidade de Belo Horizonte, quando Juscelino Kubitschek fora prefeito. Dessa maneira, propomos a leitura de que a arquitetura moderna do Colégio em si já se apresenta como uma primeira personagem ao espectador.

\section{Uma lição de História do Brasil e outra do "bom gosto"}
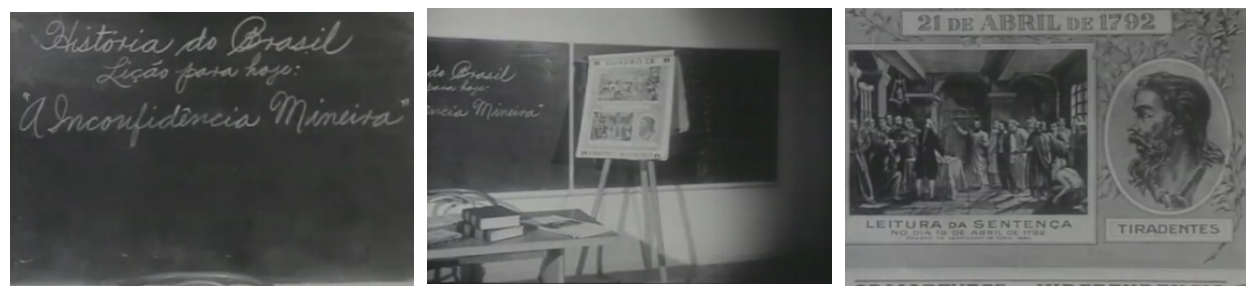

Figura 5: Painel (1950) - o professor e a sala de aula.

Ao adentrarmos junto com a câmera à sala de aula, descobrimos através do quadro negro que o tema do dia é a Inconfidência Mineira (Figura 5). Somando-se às imagens, uma voz masculina fora de campo inicia afirmando que "o ideal de Tiradentes foi afogado em sangue", sendo traído e tornado infame, mas que "deixou a semente da liberdade que vingou trinta anos depois". O discurso é narrado e o aporte imagético aos poucos vai construindo a posição da personagem que narra, ainda que não tenha sido identificada explicitamente a um professor. Nesse sentido a câmera procura construir o ambiente propício para o filme se colocar como uma aula de História do Brasil, onde observamos a lousa, livros sobre a mesa e um cartaz disposto em um cavalete, o qual é detalhado para ilustrar o tema que é desenvolvido pela narração. Dessa forma reconhecemos as ferramentas de ofício do narrador, assim como sua postura significa a “voz da autoridade", conforme conceituada por Nichols (2013) .

Prosseguindo sua fala, o narrador afirma:

A propósito desta lição, chamo a sua atenção para o painel Tiradentes, do grande pintor brasileiro Candido Portinari, existente neste colégio. Essa tela narra, com as cores fortes da pintura moderna, esse esplêndido episódio da nossa história. Convém que você observe demoradamente o painel

\footnotetext{
${ }^{8} \mathrm{O}$ autor identifica pelo menos duas vozes que podem ocorrer nos documentários por meio de letreiros ou oralizadas. A primeira corresponde a "voz de Deus", esta se caracteriza por uma voz fora de campo que transparece neutralidade e onisciência a respeito daquilo que narra. Por outro lado, a "voz de autoridade" assume a corporalidade através de uma personagem que representa uma autoridade sobre o assunto que tratado, transmitindo credibilidade para a argumentação desenvolvida. Ambas são características do "modo expositivo" e surgiram desde as origens do documentário nos anos 1920. Cf. Nichols (2013). Na cena em questão, apesar de a voz do narrador surgir em um primeiro momento fora de campo, característica da "voz de Deus", tão logo ela é identificada como fala de um professor ao percebermos que se trata de uma aula.
} 
para enriquecer os seus conhecimentos e compreender a significação dessa obra de arte, seja como pintura moderna, seja como elemento de estudo da história pátria. (Trecho de PAINEL, 1950)

Nessa passagem, temos o primeiro contato com o painel em questão, pois são mostrados detalhes a partir de uma reprodução que se encontra disposta na mesa do professor. Também se evidencia o tom de exaltação assumido pela obra, tanto em relação ao "grande pintor brasileiro" quanto ao "esplêndido episódio da nossa história". Assim como se faz necessário o registro de que a obra "narra com as cores fortes da pintura moderna”, ao menos para que o espectador possa tentar imaginar as cores enquanto assiste ao filme em branco e preto. Cabe destacarmos aqui que a decupagem continua sua estratégia marcadamente didática assumida desde o início do filme ${ }^{9}$ - através da aproximação gradual externa e interna do Colégio. Dessa forma, quando Tiradentes é citado nessa cena, por exemplo, a câmera detalha sua imagem exposta no cartaz (Figura 5), com o intuito de apresentar a personagem mencionada, assim como as imagens mostradas da reprodução do painel já procuram estabelecer um primeiro contato enquanto o narrador nos fala sobre ele.

Prosseguindo o desenvolvimento da narrativa, nos damos conta de que há um interlocutor no espaço diegético, mas que ainda não assumiu corporeidade diante das ações em cena. Surge a voz de uma criança e o filme passa a construir essa personagem que se torna coadjuvante. Assim, há o desenvolvimento das seguintes falas:

Criança: Professor, por que o senhor não aproveita esta oportunidade e vai comigo ver o painel e dar uma explicação sobre ele? Porque, francamente, até agora não compreendi nada daquilo tudo.

Professor: Boa ideia. Venha comigo! (Trecho de PAINEL, 1950)

Além de criar o ensejo para conhecermos a obra "de perto", a exemplo da construção da primeira personagem, agora a câmera identifica a fala do aluno às carteiras vazias da sala de aula. Em todas elas percebemos livros abertos no tampo. Além de enfatizar o papel de aluno da personagem que está falando, a cena nos conduz a assumirmos sua posição. Conforme ocorre no primeiro fotograma apresentado (Figura 6), o plano é desenvolvido com a fala da criança - citada anteriormente -, e a câmera faz um movimento horizontal em seu próprio eixo, da esquerda para a direita, mostrando a sala vazia, mas com as carteiras alinhadas em

${ }^{9}$ Galvão (1981) salienta que a característica didática, partindo do amplo para o específico, foi recorrente nos filmes da Vera Cruz. 
fileiras, denotando disciplina e organização. Dessa forma, é sugerido o convite para nós, na condição de espectadores, assumirmos o papel de alunos. Os planos seguintes que acompanham a fala procuram enfatizar as carteiras e seu design em diferentes ângulos, mas mantendo o enquadramento fixo.
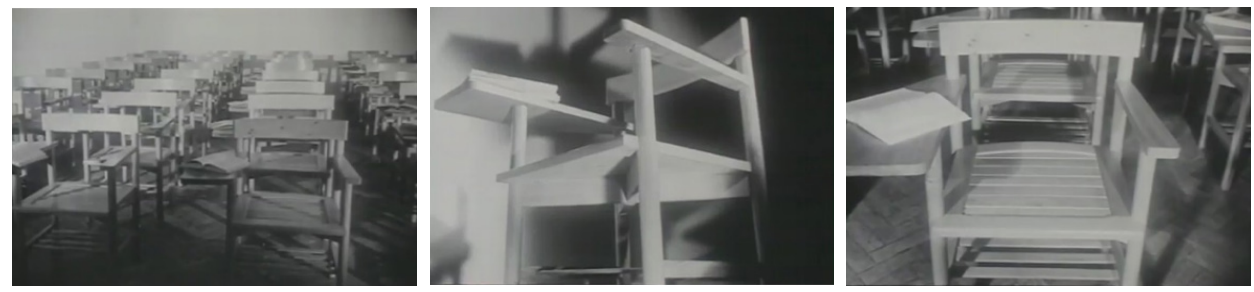

Figura 6: Painel (1950) - carteiras vazias.

Em seguida, há um plano mostrando as personagens caminhando no saguão em frente ao painel (Figura 7). Nessa cena a composição do quadro privilegia o espaço, através da perspectiva, visando salientar o grande porte do painel. Assim, as personagens se sentam em duas cadeiras dispostas ao fundo do quadro e o aluno questiona "por que é tão difícil [...] entender a pintura moderna". Em resposta, o professor diz não ser difícil e declara:

No estágio atual da pintura moderna, quando uma imensa maioria ainda se apega aos cânones artísticos de um academismo agonizante, é natural que esta obra pareça à primeira vista, para o observador desavisado, um amontoado de cenas e coisas, cores e figuras geométricas sem sentido nem significação. A idade, o estudo e a observação acabarão por modificar esse conceito da pintura moderna, abrindo-nos os olhos do entendimento e do bom gosto. (Trecho de PAINEL, 1950)

Nessa passagem se evidencia a intencionalidade de ensinar o "bom gosto" ao espectador associando-o diretamente à pintura moderna. Apresentando a "arte moderna", que somente "a idade, o estudo e a observação" seriam capazes de fornecer ferramentas para sua compreensão, o filme estabelece que se trata de uma cultura que requer um conhecimento previamente estabelecido e aperfeiçoado, colocando-o em uma ordem superior. Além disso, é sugerida a necessidade de atualização estética do meio artístico de maneira mais ampla uma vez que "uma imensa maioria ainda se apega aos cânones artísticos de um academismo agonizante”. 

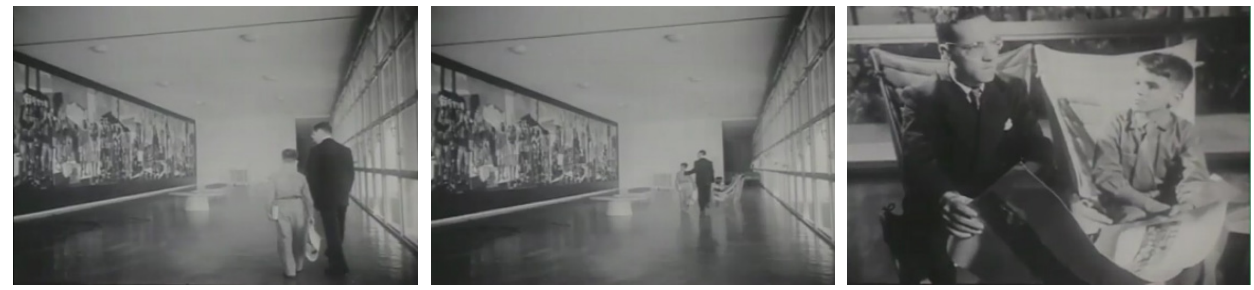

Figura 7: Painel (1950) - professor e aluno em frente ao painel.

Nesse trecho fica claro como a ênfase ao "bom gosto" se estabelece em todo o conjunto da cena conforme os planos da Figura 7. Ao encontro do discurso proferido pelo professor, acompanhamos a modernidade associada à elegância e ao bom gosto, que se evidenciam pelos trajes vestidos pelas personagens, a arquitetura em harmonia com o painel e pelo mobiliário que possui características modernas, conforme destacamos na Figura 8.

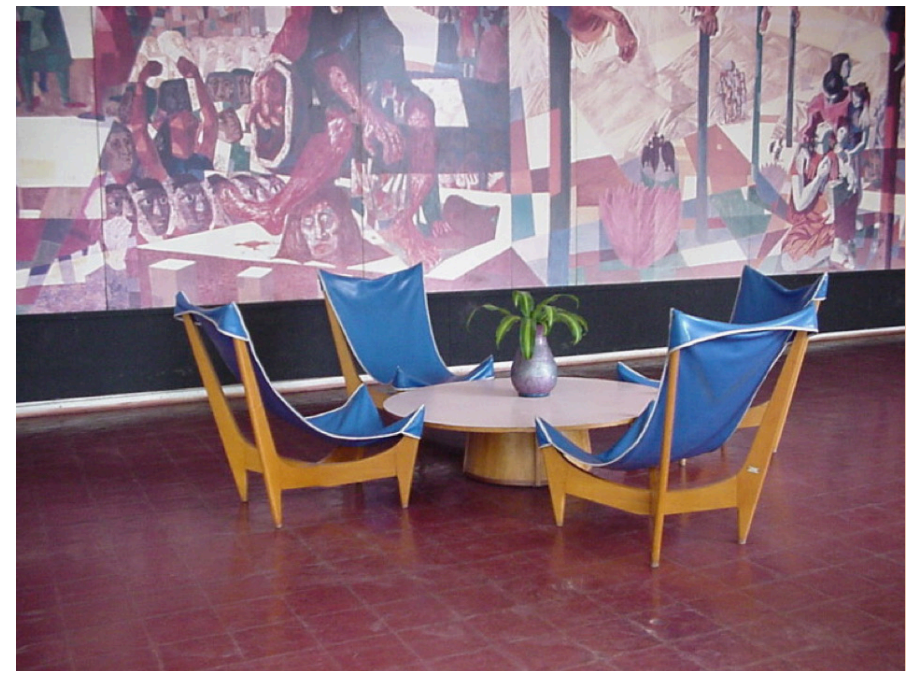

Figura 8: Mobiliário - projetado por Joaquim Tenreiro ${ }^{10}$.

O mobiliário projetado para o Colégio ficou a cargo de Joaquim Tenreiro. Para Maria Santos (1995, p. 82), Tenreiro foi o mais representativo designer de móveis brasileiro de seu período. Chegou ao Brasil em 1928, vindo de Portugal, onde aprendera com seu pai, exímio artesão, a arte de trabalhar a madeira. Conforme Maria Santos (1995, p. 84), Tenreiro pode colocar suas concepções de

${ }^{10}$ Disponível em: <https://goo.gl/P8Eu3x>. Acesso em: 26 mar. 2018. 
móvel moderno entre os anos de 1942-1969, com a fundação da "Langenbach \& Tenreiro Móveis e Decorações". Tal situação se tornou possível em 1941, quando foi contratado por Inácio Peixoto para projetar os móveis de sua residência. Peixoto havia enviado a planta da casa realizada por Niemeyer para diversos profissionais e "foram feitos vários projetos, mas nenhum satisfez o gosto do cliente, que insistiu na procura de móveis modernos" (SANTOS, 1995, p. 84), até escolher Tenreiro para realizar o projeto que foi prontamente aceito por Peixoto como definitivo. Sua loja, em 1947, já havia se firmado e na década de 1950 inaugurou uma filial em São Paulo, dedicada à venda de "móveis modernos".

Conforme Anaildo Baraçal ${ }^{11}$, as poltronas utilizadas no filme (Figuras 7 e 8) sintetizam as relações entre o design internacional e o passado nacional. A plasticidade dos encostos remete a redes indígenas, e os esteios, ao caráter funcionalista, conforme desenvolvido por Marcel Breuer na Bauhaus, em harmonia com a arquitetura do prédio. Mas, diferentemente da ênfase em tubos de aço empregada por Breuer, Tenreiro se dedicou durante sua vida a um trabalho bastante refinado com a madeira.

Sobre esse último ponto, Denis (2000, p. 162) afirma que os designers do período dos anos 1940 e início dos 1960 “se viram divididos entre nacionalismo e internacionalismo, entre tradição artesanal e progresso industrial, e os resultados foram tão diversos quanto as personalidades envolvidas nos debates". E a respeito desse ponto o autor situa a produção mobiliária de Tenreiro como representativa entre elementos que remetem à tradição e à modernidade. Diferentemente da produção internacional que se utilizava da produção industrial em larga escala, "os móveis criados por Tenreiro nessa época trazem o uso característico de madeiras de lei, como jacarandá, e de palhinha, materiais que remetem à mais antiga tradição moveleira brasileira, datando da época colonial” (DENIS, 2000, p. 164). Assim, o mobiliário de Tenreiro expressava "uma produção ao mesmo tempo modernista e artesanal, de nível internacional, mas de fortes características nacionalistas”.

\section{Os acordes da narrativa}

Após as considerações apontadas pelo professor-narrador em Painel, ele continua dizendo ao aluno para observar a pintura de Portinari, pois ela se divide "em determinada sequência, que você dentro em pouco compreenderá perfeitamente”. Sua fala é acompanhada por um travelling mostrando todo o painel, em adição à trilha musical que inicia em um andamento lento, transmitindo serenidade e entendimento

\footnotetext{
11“Cataguases: um olhar sobre a modernidade”. Disponível em: 〈https:/goo.gl/MPNi7g>. Acesso em: 28 mar. 2018.
} 
diante do que é exposto. No entanto, o próximo plano (Figura 9) cria uma ruptura nessa harmonia, sendo acompanhada pela música com o andamento mais acelerado.

Agora observamos o rosto do aluno em primeiríssimo plano enquanto movimenta a cabeça. Os planos são alternados ora com a criança, ora com a câmera subjetiva assumindo seu olhar, reproduzindo-o através de movimentos horizontais e circulares em seu próprio eixo. A ação é intensificada pela música, que agora passa a enfatizar o olhar confuso da criança. Dessa forma, com a utilização do recurso da câmera subjetiva, passamos a enxergar a obra assumindo o ponto de vista do aluno.
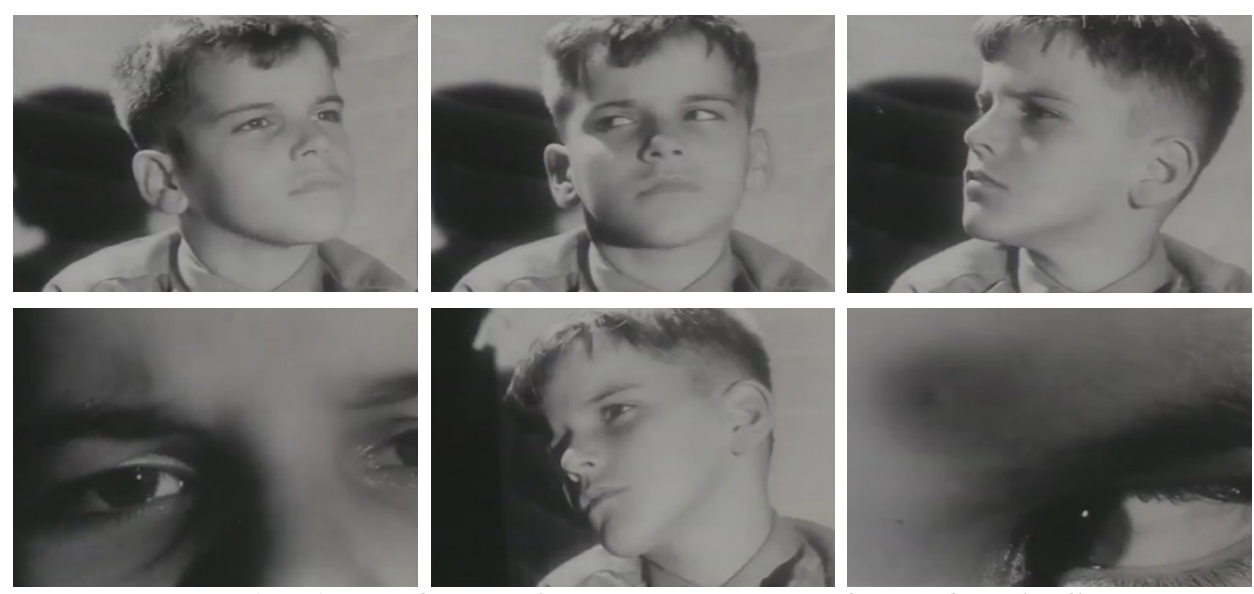

Figura 9 - Painel (1950) - o aluno confuso: em primeiríssimo plano e plano detalhe.

Após essa cena, a música regressa ao andamento anterior, juntamente com a câmera efetuando um movimento de travelling que propõe um ritmo mais lento e com o professor proferindo: "Era uma vez, na capitania de Minas Gerais...”. A partir daí o documentário passa a construir a narrativa utilizando-se fundamentalmente das imagens capturadas do painel, reconstituindo as ações tematizadas de forma linear, assim como insere letreiros que têm a função de esclarecer os fatos ocorridos e ali representados.

Em paralelo à sequência de imagens do painel, observamos os seguintes letreiros: "Conspiração"; "Julgamento"; "Execução"; "Esquartejamento"; "O corpo esquartejado, - nos campos de Minas"; "A cabeça do mártir, - em Vila Rica”; e "Libertação". Em cada cena sucedida pelos letreiros, a trilha musical se modifica visando suscitar determinados sentimentos em adição às imagens expostas. Assim, nos primeiros letreiros, ela assume um caráter de suspense e pesar, enquanto em "A cabeça do mártir, - em Vila Rica” e em "Libertação" ela passa a sugerir uma posição 
mais esperançosa e, dessa forma, destaca a redenção do "mártir", assim como o fato de que sua morte não ocorrera em vão quando em "Libertação" observamos closes na figura de mulheres rompendo correntes.
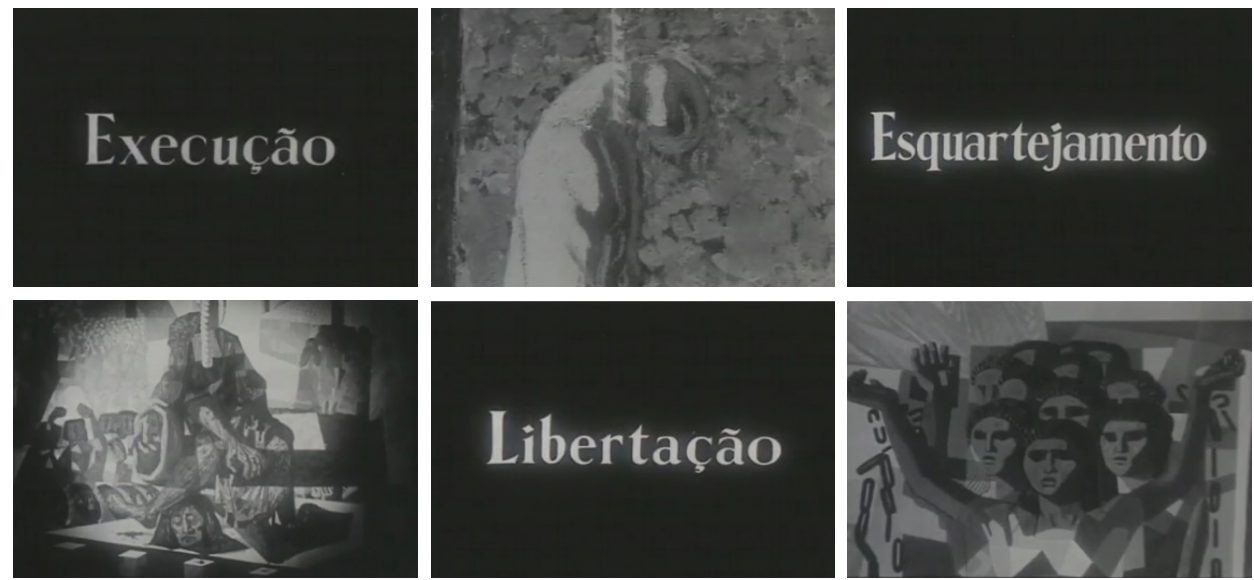

Figura 10: Painel (1950) - exemplos da intercalação entre letreiros e imagens captadas do painel.

Francisco Mignone, compositor da trilha musical de Painel, era ligado ao nacionalismo musical. Essa corrente estética surgiu na Europa no final do século XIX e tinha como característica a utilização de temas folclóricos regionais adaptados a composições eruditas. No Brasil, tal estética se tornou predominante na música de concerto nos anos 1920 e 1940. Além de Mignone, os maestros Guerra Peixe, Radamés Gnatalli e Gabriel Migliori foram engajados a esse movimento e compuseram trilhas

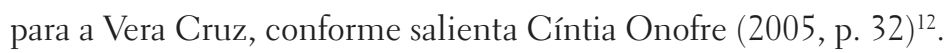

É oportuno refletirmos sobre a declaração de Mignone $^{13}$ a respeito de sua composição musical para o documentário em questão. O maestro afirma que:

Em Painel, confesso que fracassei. Pois havendo convivido com Portinari, tinha deste uma visão inteiramente diversa daquela de Lima Barreto. Foi nessa situação conflitiva que escrevi a música. Esta, segundo a concepção do diretor do filme, teria de ser fácil, popular, agradável. E eu, muito ao contrário, pensava num Portinari eclético, acadêmico, brasileiro, cheio de força interior e dotado de concepções ousadas e avançadas. Por esta razão eu e Lima Barreto não mais trabalhamos juntos. (MIGNONE apud ONOFRE, 2005, p. 275)

\footnotetext{
${ }^{12}$ Cintia Onofre (2005) disserta sobre a utilização das trilhas musicais nos dezoito filmes ficcionais longas-metragens produzidos pela Companhia Vera Cruz no seu período áureo (1950-1954), assim como traz um levantamento bibliográfico dos principais maestros/compositores envolvidos em tal processo.

${ }^{13} \mathrm{O}$ depoimento citado por Onofre foi colhido por Sérgio Barcelos em 1968.
} 
Ainda com Onofre (2005, p. 275), observamos que em suas palavras transparece mais o pesar por ter falhado diante das expectativas do diretor do que pelo êxito da trilha musical no desenvolvimento da narrativa fílmica em si. Some-se a isso o sucesso posterior do filme O cangaceiro (1953), de Lima Barreto, no qual a direção musical foi confiada a Gabriel Migliori ${ }^{14}$. Em um panorama mais amplo, Onofre (2005, p. 275) afirma que "de todos os compositores que participaram da Vera Cruz, Mignone foi o que mais vinculou seu trabalho de música erudita ao cinema".

No entanto, conforme nossa análise do presente documentário, observamos que a trilha musical de Mignone não assume apenas o papel de ornamento estético, mas desempenha bem o seu papel na construção da narrativa. Todavia, é interessante retermos tal conflito entre as expectativas do diretor e aquelas concretizadas pelo compositor. Por um lado, revelam o viés didático marcadamente assumido pela obra fílmica, levando-se em consideração que aquele esperava uma trilha "fácil, popular, agradável". Ao passo que Mignone procura justificar seu trabalho de cunho erudito pelo fato de conhecer Portinari e supor seu perfil "eclético". Além disso, não por acaso o compositor ainda o caracteriza como "brasileiro". Esse ponto possivelmente seria uma das expectativas de Lima Barreto, tendo em vista não apenas um tema nacional, partindo de um pintor brasileiro, mas que a trilha sonora viesse ao encontro de tal composição fílmica.

\section{Tiradentes: o mártir em cena}

Ainda no sentido nacional notamos o viés presente na escolha temática, pois é colocada a preocupação de conhecer a cultura brasileira partindo do "grande pintor". Ao falar sobre Tiradentes, percebemos um viés heroicizante da obra. Esse argumento se evidencia já no primeiro letreiro apresentado pelo filme, informando ao espectador que:

Êste filme é o primeiro de uma série de documentários de curta metragem que a Cia. Cinematográfica Vera Cruz pretende realizar em torno dos mais variados assuntos: desde as obras de arte - folclóricas ou não, às belezas naturais de nossa terra, os fastos da nossa história e os usos e costumes de nossa gente. (PAINEL, 1950)

Ao regredirmos temporalmente com Carvalho (2011), podemos compreender melhor de que maneira se deu o arregimento de Tiradentes enquanto símbolo

\footnotetext{
${ }^{14} \mathrm{O}$ filme foi premiado em dois festivais internacionais de prestígio: no Festival de Cannes, como melhor filme de aventura e menção especial pela música "Mulher rendeira", e foi escolhido como melhor filme no Festival de Edimburgo (RAMOS; MIRANDA, 2000, p. 44). Além da música citada, foram utilizadas outras canções baseadas no repertório popular do Nordeste brasileiro, dentre elas "Lua bonita", "Meu pinhão" e "Saudade meu bem saudade", compostas por Zé do Norte.
} 
pátrio. O autor parte do processo que se deu logo após a Proclamação da República, com a tentativa de desenhar um imaginário através da mobilização simbólica de elementos que pudessem identificar o povo com o novo regime que se instituía. Uma vez que a Proclamação se tratou de uma "passeata militar", conforme o autor, fizeram-se necessárias tais construções com o propósito de criar a identificação civil com a República militar que se instituía.

Nessa perspectiva, buscavam o propósito de construir uma unidade nacional, e tão logo a figura de Tiradentes foi idealizada em associação à figura de Cristo e por seu martírio. Tanto pelo apelo à religiosidade do povo quanto por criar a característica cívica em oposição a uma postura radical, garantiria a integração entre diversas posturas republicanas. Tal construção havia se iniciado ainda no período monárquico, em meados do XIX, mas se oficializa com a Proclamação da República, sendo logo declarado em 1890 o feriado nacional de 21 de abril.

Conforme salientado por Freitas (2013, p. 255),

ao longo da história, a imagem de Tiradentes ganhou muitas e diferentes versões, de conspirador infiel a herói da República, passando por cristão exemplar e mártir da independência, numa inconstância simbólica que variou conforme os interesses de cada contexto de apropriação. (FREITAS, 2013, p. 255)

Nesse sentido, devemos considerar o fato de que a Companhia Cinematográfica Vera Cruz pretendia exportar seus filmes e, assim, poderia mostrar ao mundo que no Brasil existia cultura de “alto nível”. Conforme o dizer de Galvão (1981, p. 257), "documentar cultura tem ao mesmo tempo a vantagem de poder mostrar ao mundo que, por mais subdesenvolvidos que sejamos, nós temos arte comparável à de qualquer país civilizado”. Ainda destacamos a força que o tema em questão atinge ao ser levado as salas de cinema do público estrangeiro. O processo de heroicização criado pelo filme com Tiradentes e a Inconfidência Mineira, ocorrida em 1789, poderia inserir o Brasil nas peculiaridades caras às nações desenvolvidas e ser visto por esse público estrangeiro, estabelecendo como parâmetros eventos ocorridos no contexto em questão, a Independência dos Estados Unidos (1776) e a Revolução Francesa (1789).

Para tal, a obra se utiliza do prestígio de Portinari, uma vez que esse já havia se consagrado como pintor ainda na década de 1930. Dessa forma, Portinari autenticaria a relevância da obra, e quando a personagem do professor cita os "cânones artísticos de um academismo agonizante", ele se posiciona a favor da arte moderna, mas ainda apegada aos elementos figurativos, que não havia absorvido o primado da imagem proposto pelas artes abstratas e que só seria absorvido no Brasil 
no decorrer da década em questão, mas que já estava na pauta de discussões em torno da arte moderna brasileira no início dos anos 1950.

Complementando nossa argumentação, chamo a atenção para a forma com que o documentário em questão olha para o passado. Em Painel percebemos nos minutos iniciais que o tema é a Inconfidência Mineira e Tiradentes. Apesar de o narrador situar a obra de Portinari e o filme se desenvolver em torno dela, o foco está em compreender os eventos representados na obra e não no entendimento da pintura moderna em si, conforme sugere o narrador no início da película. Nesse quesito, a partir do distanciamento estabelecido em relação ao passado que busca legitimar/diferenciar o presente da obra daquele tratado, percebemos que a obra de arte moderna de Portinari é utilizada como meio para tratar do tema Tiradentes. Essa que, aliada à arquitetura, ao design do mobiliário do prédio e à trilha musical, constrói o ideal de modernidade pretendido.

\section{Referências}

AMARAL, A. Arte Para quêe? a preocupação social na arte brasileira, 1930-1970: subsídios para uma história social da arte no Brasil. São Paulo: Studio Nobel, 2003.

ARGAN, G. C. Arte Moderna: do Iluminismo aos movimentos contemporâneos. São Paulo: Companhia das Letras, 2010.

AZEVEDO, Á. de. Lira dos vinte anos e poesias diversas. São Paulo: Ateliê Editorial, 1999.

CARVALHO, J. M. de. A formação das almas: o imaginário da República no Brasil. São Paulo: Companhia das Letras, 2011.

DENIS, R. C. Uma introdução à história do design. São Paulo: Edgard Blücher, 2000.

EGG, A. Modernismo musical e colaboração internacional na Política de Boa Vizinhança. Baleia na Rede, Marília, v. 1, n. 10, p. 62-81, 2013.

FICHER, S.; ACAYABA, M. M. Arquitetura moderna no Brasil. São Paulo: Projeto, 1982.

FREITAS, A. Arte de guerrilha: vanguarda e conceitualismo no Brasil. São Paulo: Edusp, 2013.

GALVÃO, M. R. Burguesia e cinema: o caso Vera Cruz. Rio de Janeiro: Civilização Brasileira, 1981.

MILLIET, M. A. Tiradentes: o corpo do herói. 1998. Tese (Doutorado em Estruturas Ambientais Urbanas) - Faculdade de Arquitetura e Urbanismo, Universidade de São Paulo, São Paulo, 1998. 
NICHOLS, B. Introdução ao documentário. Campinas: Papirus, 2013.

ONOFRE, C. C. O zoom nas trilhas da Vera Cruz: a trilha musical da companhia cinematográfica Vera Cruz. 2005. Dissertação (Mestrado em Multimeios) - Instituto de Artes, Universidade de Campinas, Campinas, 2005.

PORTINARI, C. Tiradentes. 1948. 1 original de arte, painel a têmpera em tela, $309 \times$ 1767 cm. Disponível em: <https://goo.gl/QTxjfP>. Acesso em: 26 mar. 2018.

RAMOS, F. P.; MIRANDA, L. F. A. de. (Orgs.). Enciclopédia do cinema brasileiro. São Paulo: Senac São Paulo, 2000.

SANTOS, C. R. dos; LAGE, C. F. Cataguases: patrimônio da modernidade (1). Arquitextos, ano 5, jan. 2005. Disponível em: <https://goo.gl/QCACgm>. Acesso em: 26 mar. 2018.

SANTOS, I. D. Enquadrando a nação: a cultura nacional e a Companhia Cinematográfica Vera Cruz no início dos anos 1950. 2015. Dissertação (Mestrado em História) - Universidade Federal do Paraná, Curitiba, 2015.

SANTOS, M. C. L. dos. Móvel moderno no Brasil. São Paulo: Edusp, 1995.

SILVA, E. de C. As representações do Colégio de Cataguases e de suas práticas educativas nas memórias de seus ex-alunos. (Década de 1950). 2005. Dissertação (Mestrado em Educação e Cultura Contemporânea) - Programa de Pós-Graduação em Educação, Universidade Estácio de Sá, Rio de Janeiro, 2005.

TOLENTINO, C. A. F. O rural no cinema brasileiro. São Paulo: Unesp, 2001.

TOTA, A. P. O imperialismo sedutor: a americanização do Brasil na época da Segunda Guerra. São Paulo: Companhia das Letras, 2000.

XAVIER, I. Sertão mar: Glauber Rocha e a estética da fome. São Paulo: Cosac Naify, 2007.

Referências audiovisuais

PAINEL. Lima Barreto, Brasil, 1950. (16 min).

submetido em: 30 set. 2017 | aprovado em: 13 nov. 2017 